\title{
Industry 4.0 in SMEs: a sectorial analysis
}

\author{
Javier Luco $^{1}$, Sara Mestre ${ }^{1}$, Ludovic Henry ${ }^{1}$, Simon Tamayo ${ }^{1}$, Frederic Fontane ${ }^{1}$ \\ ${ }^{1}$ Centre for Robotics \\ MINES ParisTech- PSL Paris \\ Research University \\ Paris, France
}

\begin{abstract}
The diffusion of Industry 4.0 within companies depends on their size. The resources and processes of large companies are more structured, so they are likely to deploy 4.0 technologies more quickly than SMEs. In order to prevent these SMEs from becoming victims of this industrial revolution, it is essential to fully understand the organizational, human and technological challenges of Industry 4.0. This article presents a review of the barriers and problems that a 4.0 investment can create for small and medium-sized businesses depending on their sector. Our analysis proposes a synthesis matrix with the effects of industry 4.0 in the different sectors of SMEs. This matrix presents the impacts, opportunities and risks of each of the main technologies of industry 4.0. Based on process innovations such as training plans or customer proximity, SMEs seem to have adopted their own Industry 4.0 concepts according to their sectors of activity.
\end{abstract}

Keywords: Industry 4.0; Small and Medium-Sized Enterprises; Sectorial Analysis

\section{Introduction}

SMEs are independent companies with a limited number of employees. This number varies according to the national files of the different countries. The most common standard is 250 employees with a total turnover not exceeding EUR 50 million [1], in particular in the European Union. The United States considers SMEs to include all companies with less than 500 employees (OECD). In France, for example, small, medium and micro enterprises represent nearly $48.5 \%$ of jobs [2].

The world has experienced 3 major industrial revolutions. Today, a fourth revolution is taking shape: Industry 4.0. Its roots are at the dawn of the third millennium with the emergence of the Internet. This revolution does not stem from a new energy source but from the potential of a new technological phenomenon: digitalization. The survival of SMEs therefore depends largely on their ability to respond to these new industrial challenges.

In the manufacturing industry, which accounts for the largest share of industrial production, about 10 percent of firms are currently making intensive efforts to integrate Industry 4.0 [3]. There is a significant relationship between company size and Industry 4.0 implementation [3]. Large companies are much more advanced in inte- 
grating information technology systems into their production facilities. Various surveys [3] have reached similar conclusions, demonstrating that only $13 \%$ of small and medium-sized enterprises in the manufacturing industry have already integrated 4.0 into their facilities and systems; $17.5 \%$ have committed to it and developed their first concrete implementation plans; just under $40 \%$ are reviewing them; and about $25 \%$ of SMEs have not yet considered integrating this new industry [3].

The aim of this study is to understand where SMEs stand in the face of this digitalization of society. The great strength of small and medium-sized enterprises lies in the adaptability and reactivity of the market [4]. Is it possible that digital only benefits companies with more than 500 employees? What types of SMEs benefit from Industry 4.0, and to what extent? Why is it more complicated for SMEs to adapt to this new technology? Why don't they visualize its adaptation? What are SMEs using to integrate Industry 4.0? In order to try to address all these questions, it is essential to understand whether small and medium-sized enterprises have the necessary skills and knowledge to carry out this process independently or whether they need a specialized integrator. The idea of an apprenticeship plan offers the possibility to support companies in this process [5], as industrial companies trying to implement Industry 4.0 face a number of challenges and constraints.

The question for SMEs is: When is the right time to integrate these technologies? Many actors in the fields of science, politics and economics feel the need to actively support the digitalization process. Nevertheless, SMEs lack the resources to invest in research and development activities, they struggle to manage complex IT solutions and lack the expertise to integrate new technologies [6].

\section{Analytical framework}

\subsection{Diagnostic and framework of the general market}

It should be noted that there are two types of SMEs: the goods and the services sectors. The figures in this section include all SMEs selling market goods, i.e. all tangible and intangible products (goods and services). In order to better focus our study, it is important to define an analytical framework. Let is start by defining the challenges of the SME market in relation to Industry 4.0.

SMEs are the backbone of economies and guarantee the good health of the European economy. In response to trends in globalization and international interconnectivity, SMEs are selling more products and services to foreign markets, while competitiveness continues to increase. In recent years, the trend towards automation and data exchange in manufacturing has become increasingly important for today's companies [7]. This trend has a number of implications for workers, ranging from technological changes to social effects. The definitions of the term Industry 4.0 are diverse and extremely varied, but essentially describe an integrated network of digitized and web-based machines and products [8]. In this article, we will use the following definition: Industry 4.0 is the integration of digital systems to control physical systems. It is therefore characterized by the integration of digital technologies into the global manufacturing process. 
According to [9], SMEs employ the majority of the workforce in services for private individuals, commercial crafts (bakery, delicatessen, pastry), and specialized scientific and technical activities (including liberal professions). Similarly, in construction, other than a dozen large companies, three-quarters of all employees are employed by SMEs. We have therefore decided to select the 3 most important sectors in terms of number of employees by sector of activity and category of company based on 2015 figures according to [9]:

- Commerce, transport, accommodation and catering (1)

- Industry (2).

- Specific activities, scientific, technological activity. Services, administration (3).

With regards to the ranking used previously, we noted that industry action 4.0 is more easily identifiable and quantifiable in SMEs producing services. The technologies of 4.0 are terrific at providing the means to connect with customers or partners by setting up autonomous processes [6]. Digital technology, data study and the connection between customer and production unit have given birth to a factory generation: Smart Factor [7]. This phase of business transformation is characterized by the digitalization of companies at the heart of their industrial strategy and processes.

\subsection{Measuring digitalization in companies}

Digitalization is becoming a major issue on a global level and we are seeing it on both an industrial and political level. It is not insignificant to note that several countries today consider digitalization via Industry 4.0 to be strategic [10]. To fill the lack of resources for SMEs to invest in research and development activities [6], several governments, particularly in Europe, have made financial aid available to develop alternative solutions in 4.0 (European Parliament-2016). In France, for example, aid for industrial SMEs was approved in 2017. This allows up to $40 \%$ of digital and digital investments to be deducted from their taxable profits (French Government-2017). According to Eurostat (2016), the French government is ranked first in the implementation of education and training policies for Industry 4.0 compared to its European neighbors (UK, Germany, Italy).

\subsection{The great impact in value of Industry 4.0}

To conclude this part of the analytical framework, we would like to highlight a study published by the World Economic Forum, which shows the impact of digitalization in terms of cumulative value. In the different sectors we have chosen to isolate, we note that the impact of digitalization plays an important role. These results show the impact of digitalization in terms of cumulative value for the years 2016 to 2025 (The future of trade - The impact of digitalization: Cumulative value of digitalization to industries, 2018). Based on the results of this study, we find that the sector most affected by far is the one directly affecting the final consumer. The accumulated value of digitization is nearly US $\$ 5,000$ trillion, which corresponds mainly to the digitization of services dedicated to consumers such as shops, transport, accommodation and restaurants. 


\section{$3 \quad$ Types of SMEs versus Industry 4.0}

The OECD conducted a study on automation risk by job type, so it seemed appropriate to us to isolate the top 9 high-risk occupations in this study. The study highlights that $14 \%$ of jobs in the 32 countries studied are highly vulnerable to 4.0 technologies, i.e. they have at least a $70 \%$ chance of being automated. We therefore believe that these 9 sectors are the companies' targets for implementing 4.0. This confirms the research work of Ruessmann (2015) [11].

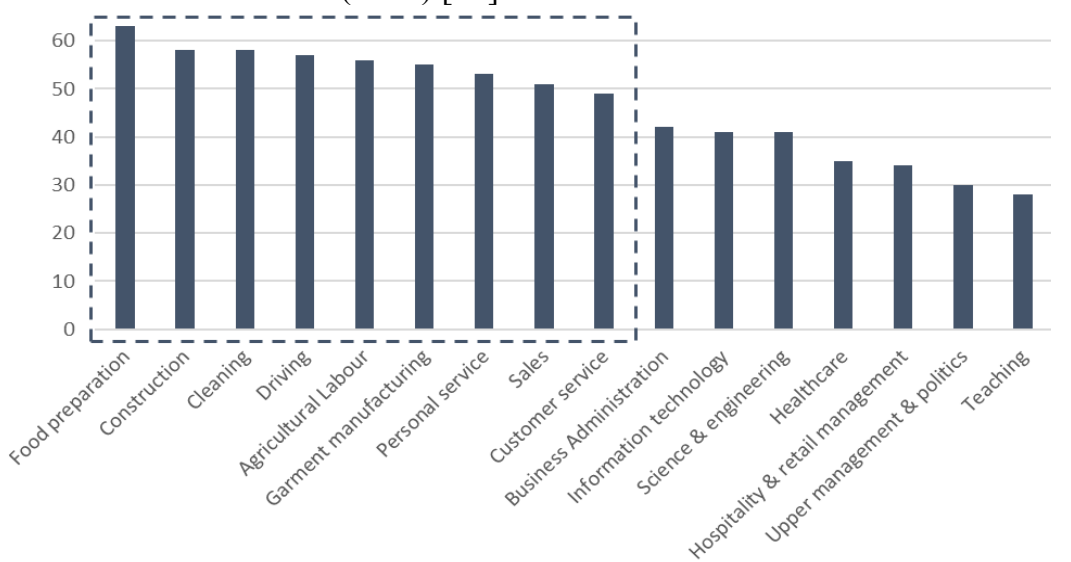

Fig. 1. Automation risk by job type (\%)

Thanks to the study carried out by the OECD, we proceeded to cross-check information between the main axes of Industry 4.0 defined by [11] and [12], with trades at risk in terms of employability in the context of the integration of Industry 4.0.

The matrix synthesis (Table 1) therefore presents this cross-reference of information. We found an important difference in the development of the different axes of Industry 4.0 in the applicability of the job sectors that the OECD agreed had a high risk of automation. The table below shows, for each of the industry sectors, a summary of the articles that have studied the jobs at risk, including risks and potential depending on the case and the applicability.

Table 1. Synthesis matrix of effects of industry 4.0 in SMEs sectors

\begin{tabular}{|c|c|c|c|}
\hline Axes & Sector & Findings & Ref. \\
\hline \multirow[t]{4}{*}{ Big Data } & $\begin{array}{l}\text { Food prepa- } \\
\text { ration }\end{array}$ & $\begin{array}{l}\text { Uses of big data, looking specifically at how these techniques and technologies } \\
\text { govern our ability to imagine food worlds. }\end{array}$ & [13] \\
\hline & $\begin{array}{l}\text { Agricultural } \\
\text { labour }\end{array}$ & $\begin{array}{l}\text { Agricultural remote sensing data, as general remote sensing data, have all the } \\
\text { characteristics of big data }\end{array}$ & {$[14]$} \\
\hline & Sales & $\begin{array}{l}\text { The forecasting of sales in the supply chain could be enhanced by customer } \\
\text { analytics based on big data and associated technologies. }\end{array}$ & {$[15]$} \\
\hline & $\begin{array}{l}\text { Customer } \\
\text { service }\end{array}$ & $\begin{array}{l}\text { The intelligent customer relationship network usually uses the customer's equip- } \\
\text { ment's movement trajectory data, customer platform operating data, customer } \\
\text { network base stations, and other content as customer behaviour data. }\end{array}$ & [16] \\
\hline Autonomous & Food prepa- & Food processing plants are using automation solutions, which are cost effective & [17] \\
\hline
\end{tabular}




\begin{tabular}{|c|c|c|c|}
\hline \multirow[t]{4}{*}{ Robots } & ration & \multicolumn{2}{|l|}{ for higher production volume as compared to the conventional processes. } \\
\hline & Construction & $\begin{array}{l}\text { The resulting relative poses uncertainty between the mobile robot and its work- } \\
\text { piece would likely exceed that permitted by the construction process, thereby } \\
\text { preventing the robot from performing work reliably. }\end{array}$ & [18] \\
\hline & $\begin{array}{l}\text { Agricultural } \\
\text { labour }\end{array}$ & $\begin{array}{l}\text { Automatons are more economically feasible than conventional systems because } \\
\text { the former perform tasks faster, improve productivity by working more hours and } \\
\text { reduce the amount of herbicides required, among other benefits. }\end{array}$ & [19] \\
\hline & Cleaning & $\begin{array}{l}\text { The development of a robotic system designed to clean the outer surface of } \\
\text { elliptic tapered structures such as Dubai airport concourse. }\end{array}$ & [20] \\
\hline \multirow[t]{4}{*}{ Simulation } & $\begin{array}{l}\text { Food prepa- } \\
\text { ration }\end{array}$ & $\begin{array}{l}\text { The use of agent-based simulation has increased in agri-food supply chains } \\
\text { (ASC) research in recent years. }\end{array}$ & [21] \\
\hline & $\begin{array}{l}\text { Agricultural } \\
\text { labour }\end{array}$ & $\begin{array}{l}\text { Multi agent systems are a good way to understand a complex system by imple- } \\
\text { menting simple and easy-to-understand local interaction rules. }\end{array}$ & [22] \\
\hline & Sales & $\begin{array}{l}\text { Sales and operations planning is a challenging issue to improve customer satis- } \\
\text { faction and control production costs solutions. Based on simulation, it can be } \\
\text { easily tuned to reach optimization and best fit the industrial context while incor- } \\
\text { porating specific characteristics. }\end{array}$ & [23] \\
\hline & $\begin{array}{l}\text { Customer } \\
\text { service }\end{array}$ & $\begin{array}{l}\text { For better customer satisfaction, order processing service simulations such as } \\
\text { design customization need to analyse customer behaviour and evaluate product } \\
\text { lead-time. }\end{array}$ & [24] \\
\hline $\begin{array}{l}\text { Augmented } \\
\text { Reality }\end{array}$ & $\begin{array}{l}\text { Customer } \\
\text { service }\end{array}$ & $\begin{array}{l}\text { The study of [24] highlights the influence that recent technological advances in } \\
\text { virtual reality can have on the customer experience. }\end{array}$ & [25] \\
\hline \multirow{2}{*}{$\begin{array}{l}\text { Additive } \\
\text { Manufactur- } \\
\text { ing }\end{array}$} & $\begin{array}{l}\text { Food prepa- } \\
\text { ration }\end{array}$ & $\begin{array}{l}\text { Three-dimensional printing systems that accept both food ingredients and print- } \\
\text { ing materials are known as 3D food printers. }\end{array}$ & [26] \\
\hline & Construction & $\begin{array}{l}\text { Reduce labour costs, reduce material waste and create custom complexes of } \\
\text { geometries that are difficult to achieve with conventional techniques. }\end{array}$ & [27] \\
\hline $\begin{array}{l}\text { Cyber } \\
\text { Security }\end{array}$ & Driving & $\begin{array}{l}\text { Safety is a fundamental concern in modern vehicle systems. This technology is } \\
\text { vulnerable to hacking and malware, making it important for cyber security to } \\
\text { analyse potential attacks and their impact on the safety of vehicle users. }\end{array}$ & [28] \\
\hline $\begin{array}{l}\text { Systems } \\
\text { Integration }\end{array}$ & Construction & $\begin{array}{l}\text { Architecture, engineering, construction and facilities management are applying. } \\
\text { These integration technologies enable the collaborative use of information } \\
\text { throughout the product and project life cycle, and allow for greater integration of } \\
\text { people, processes and business systems, sharing information more effectively }\end{array}$ & [29] \\
\hline \multirow[t]{2}{*}{$\begin{array}{l}\text { Internet } \\
\text { of Things }\end{array}$} & Driving & $\begin{array}{l}\text { Connected cars are becoming a common sight on our roads. We will see innova- } \\
\text { tion occur much faster than ever thought possible as the ubiquity of fast networks } \\
\text { collides with the availability of high-powered software. }\end{array}$ & [30] \\
\hline & $\begin{array}{l}\text { Customer } \\
\text { service }\end{array}$ & $\begin{array}{l}\text { Changed the relationship between traditional customer networks, and traditional } \\
\text { information dissemination has been affected. Smart environment accelerates } \\
\text { changes in customer behaviour. }\end{array}$ & [31] \\
\hline
\end{tabular}

Based on the information provided by the synthesis matrix, we compared the different sectors according to the presence of various 4.0 technologies and obtained the radar shown in Fig. 2. It can be noted that the "construction" and "customer service" sectors are those that show the greatest presence in terms of the installation of tech- 
nologies. On the other end of the scale, the cleaning and sales sectors have implemented these technologies in a lesser way.

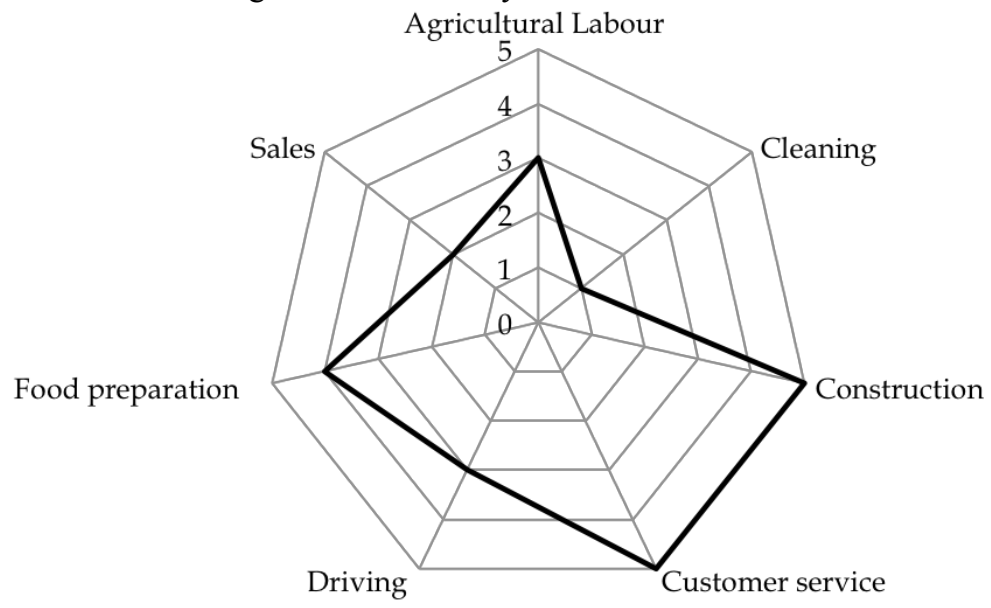

Fig. 2. Presence of 4.0 technologies by sector

\section{Conclusion and perspectives}

This paper discussed the implementation of Industry 4.0 in SMEs. After exploring the foundations of Industry 4.0 and the existing literature relating this subject to SMEs, it was found that there is a significant relationship between the size of a company and the implementation of Industry 4.0. Large companies are much more advanced in integrating information technology systems into their production facilities. For SMEs, it is more difficult due to the investments required and the challenges that come with integrating 4.0. However, to compensate for lack of funds, governments have released many financial aids. In addition, the application of 4.0 in SMEs is characterized by the integration of new internal processes such as the reorganization of flows to increase flexibility and training. Training employees to master these new technologies is a major challenge for both companies and governments.

In response to this observation, we conducted a literature review to determine which sectors were the most important in terms of number of employees, namely: (i) Trade, Transport and Accommodation; (ii) Industry; and (iii) Services and Administration (3). In order to establish a link with digitalization, we highlighted the most important sector in terms of investment in digitalization: the service sector. The service sector is very important from an economic point of view and is also the sector that has invested the most in digitalization.

Compared to previous studies on the implementation of Industry 4.0 , this article provides a synthesis matrix based on scientific sources, which includes the different industrial sectors and the different technologies that are used in each of them. This matrix allowed a cross-analysis between the sectors most vulnerable to change and the type of digitalization with high potential already in place. Our synthesis of the reviewed works allowed us to identify the SMEs sectors with highest levels of 4.0 
implementation, which are: "construction", "customer service" and "food preparation".

Industry 4.0 offers real opportunities to increase flexibility and simplify operational management. SMEs can clearly benefit from 4.0 if they establish a solid training and financing plan. The investments are significant, but the effects are quickly visible and allow significant savings in terms of cost. Developing 4.0 operating systems will make manufacturing systems more flexible and allow for better product customization by creating a close relationship with their customers. Finally, to deepen and complete our study, it seems relevant to us to make a comparison between Industry 4.0, SMEs and employability because we still have little backward step on the creation and/or destruction of jobs with regard to these new technologies.

Our literature review has some limitations. First, it is a qualitative study that does not quantify the impact that may or may not generate the presence of SMEs within the industry. Based on available information, it seeks to generate a summary of the current state of the development of the different technologies, but this does not rule out the possibility that companies may be found in sectors that were not considered in this study. Future research should focus on investigating the most attractive technologies to implement depending on the sector. This should include what investments should be made according to sector and what economic impact including any of these technologies would have on a company.

\section{References}

[1] C. D. E. S. Communaut, E. Bruxelles, D. Du, P. Europ, and E. Conseil, "FR FR,” vol. 0193, 2008.

[2] "Rapport d' activité," 2016.

[3] C. Schröder, "The Challenges of Industry 4.0 for Small and Medium-sized Enterprises Digitalisierungsprozesse im industriellen Mittelstand View project," 2016.

[4] C. Houlgatte and I. Djou, "Qualigilité : proposition pour la performance des petites et moyennes organisations," IRBM, vol. 37, no. 5-6, pp. 194-197, 2016.

[5] T. Wienbruch, S. Leineweber, D. Kreimeier, and B. Kuhlenkötter, "Evolution of SMEs towards Industrie 4.0 through a scenario based learning factory training," Procedia Manuf., vol. 23, no. 2017, pp. 141-146, 2018.

[6] A. Moeuf, R. Pellerin, S. Lamouri, S. Tamayo-Giraldo, and R. Barbaray, "The industrial management of SMEs in the era of Industry 4.0," Int. J. Prod. Res., vol. 56, no. 3, pp. 1118-1136, 2018.

[7] P. K. Muhuri, A. K. Shukla, and A. Abraham, "Engineering Applications of Artificial Intelligence Industry 4 . 0: A bibliometric analysis and detailed overview," Eng. Appl. Artif. Intell., vol. 78, no. November 2017, pp. 218-235, 2019.

[8] R. Glass, A. Meissner, C. Gebauer, S. Stürmer, and J. Metternich, "Identifying the barriers to Industrie 4.0," Procedia CIRP, vol. 72, pp. 985-988, 2018.

[9] H. Albertini et al., "Tableaux de l'économie française.," p. 274, 2018.

[10] L. Barreto, A. Amaral, and T. Pereira, "Industry 4.0 implications in logistics: an overview," Procedia Manuf., vol. 13, pp. 1245-1252, 2017.

[11] T. Future and M. Industries, "Industry 4.0."

[12] A. Luque, M. E. Peralta, A. de las Heras, and A. Córdoba, "State of the Industry 4.0 in the Andalusian food sector," Procedia Manuf., vol. 13, pp. 1199-1205, 2017.

[13] M. Carolan, "Big data and food retail: Nudging out citizens by creating dependent consumers," 
Geoforum, vol. 90, no. December 2017, pp. 142-150, 2018.

[14] Y. Huang, Z. xin CHEN, T. YU, X. zhi HUANG, and X. fa GU, "Agricultural remote sensing big data: Management and applications,” J. Integr. Agric., vol. 17, no. 9, pp. 1915-1931, 2018.

[15] B. Li, E. Ch'ng, A. Y. L. Chong, and H. Bao, "Predicting online e-marketplace sales performances: A big data approach," Comput. Ind. Eng., vol. 101, pp. 565-571, 2016.

[16] E. Park, "The role of satisfaction on customer reuse to airline services: An application of Big Data approaches,” J. Retail. Consum. Serv., vol. 47, no. November 2018, pp. 370-374, 2019.

[17] Z. H. Khan, A. Khalid, and J. Iqbal, "Towards realizing robotic potential in future intelligent food manufacturing systems," Innov. Food Sci. Emerg. Technol., vol. 48, pp. 11-24, 2018.

[18] K. M. Lundeen, V. R. Kamat, C. C. Menassa, and W. Mcgee, "Automation in Construction Autonomous motion planning and task execution in geometrically adaptive robotized construction work," Autom. Constr., vol. 100, no. October 2018, pp. 24-45, 2019.

[19] X. Krasniqi and E. Hajrizi, "Use of IoT Technology to Drive the Automotive Industry from Connected to Full Autonomous Vehicles," IFAC-PapersOnLine, vol. 49, no. 29, pp. 269-274, 2016.

[20] H. Sadjadi and M. A. Jarrah, "Autonomous cleaning system for Dubai International Airport," J. Franklin Inst., vol. 348, no. 1, pp. 112-124, 2011.

[21] D. S. Utomo, B. S. Onggo, and S. Eldridge, "Applications of agent-based modelling and simulation in the agri-food supply chains,” Eur. J. Oper. Res., vol. 269, no. 3, pp. 794-805, 2018.

[22] R. Reulier, D. Delahaye, and V. Viel, "Agricultural landscape evolution and structural connectivity to the river for matter flux, a multi-agents simulation approach," Catena, vol. 174, no. February 2018, pp. 524-535, 2019.

[23] L. L. Lim, G. Alpan, and B. Penz, "A simulation-optimization approach for sales and operations planning in build-to-order industries with distant sourcing: Focus on the automotive industry," Comput. Ind. Eng., vol. 112, pp. 469-482, 2017.

[24] T. Hara and T. Arai, "Simulation of product lead time in design customization service for better customer satisfaction," CIRP Ann. - Manuf. Technol., vol. 60, no. 1, pp. 179-182, 2011.

[25] C. Flavián, S. Ibáñez-Sánchez, and C. Orús, "The impact of virtual, augmented and mixed reality technologies on the customer experience," J. Bus. Res., no. January, pp. 1-14, 2018.

[26] S. Jayaprakash, I. F. Ituarte, and J. Partanen, "Prosumer-Driven 3D Food Printing," Fundam. 3D Food Print. Appl., vol. 2024, pp. 331-354, 2019.

[27] D. Delgado Camacho et al., "Applications of additive manufacturing in the construction industry - A forward-looking review," Autom. Constr., vol. 89, no. August 2017, pp. 110-119, 2018.

[28] L. Pan, X. Zheng, H. X. Chen, T. Luan, H. Bootwala, and L. Batten, "Journal of Information Security and Applications Cyber security attacks to modern vehicular systems," J. Inf. Secur. Appl., vol. 36, pp. 90-100, 2017.

[29] W. Shen et al., "Systems integration and collaboration in architecture, engineering, construction, and facilities management: A review," Adv. Eng. Informatics, vol. 24, no. 2, pp. 196-207, 2010.

[30] R. Kirk, "Cars of the future: The Internet of Things in the automotive industry," Netw. Secur., vol. 2015, no. 9, pp. 16-18, 2015.

[31] G. Reina, A. Milella, R. € El Rouveure, M. Nielsen, R. Worst, and M. R. Blas, "Special Issue: Robotic Agriculture Research Paper Ambient awareness for agricultural robotic vehicles," Biosyst. Eng., vol. 146, pp. 114-132, 2016. 